\title{
Comparison of Canal Transportation and Centric Ability of Two Nickel-Titanium Rotary Systems Using Cone Beam Computed Tomography: An In Vitro Study
}

\author{
Aditi Soni $^{1}$ Anjali Oak ${ }^{1}$ \\ 1Department of Conservative Dentistry, Endodontics and Esthetics, \\ CDSRC, Gujarat University, Ahmedabad, Gujarat, India
}

Address for correspondence Anjali Oak, MDS, Department of Conservative Dentistry, Endodontics \& Esthetics, CDSRC, Gujarat University, Ahmedabad 380058, Gujarat, India (e-mail: oakanjalia@gmail.com).

\begin{abstract}
Keywords

- canal transportation

- centering ability

- cone beam computed tomography
\end{abstract}

\section{Introduction}

Shaping of the root canal is one of the most critical steps for subsequent procedures and treatment outcome because it removes all the content of canal including microorganisms. ${ }^{1}$

According to Schilder, the root canal preparation should develop a continuous tapering cone and preserve the natural curve of canal. ${ }^{2}$ However, the complex anatomy of root canal system including curvature poses challenges, and ultimately treatment outcome can be affected. ${ }^{3}$ Civijan $^{4}$ was one of the first investigators who proposed (nickel-titanium [NiTi]) alloy in endodontics in 1975 . Further suggested by Walia et al (1988), ${ }^{5} \mathrm{NiTi}$ alloy facilitates the instrumentation in curved canals. In the past few years, many modifications have been made in the instrument design such as decreasing the instrument number to complete the root canal shaping. This has

received

September 18, 2018 accepted after revision November 13, 2018 published online January 10, 2019 led to faster completion of the root canal procedure, but the chance of iatrogenic error still remains because it is operator dependent. Hence, there is a need for research, which is aimed at consolidating a safe instrumentation technique that promotes effective cleaning and shaping along with maintaining the original canal shape, without causing transportation or loss of centricity.

One Shape (Micro Mega, Besançon, France) is the single-file rotary system that operates in continuous rotation and has a noncutting safety tip and three different crosssectional zones with variable pitch that reduces instrument screwing effect. ${ }^{6}$

The Mani Silk (Mani Utsunomiya, Tochigi, Japan) is a two-file system after orifice shaping. This system claims to possess flexibility, cutting efficiency, and fracture resistance because of its design and heat treatment. ${ }^{7}$
(C2018 Bhojia Dental College and Hospital affiliated to Himachal Pradesh University

License terms 
Hence, the aim of this study was to compare canal transportation and centric ability of Mani Silk and One Shape in curved canals of extracted human permanent teeth with the help of cone beam computed tomography (CBCT).

\section{Materials and Methods}

Specimen Selection: Total of 40 extracted human permanent maxillary molars with at least one curved mesial root and curved mesiobuccal root canals were selected with an angle of curvature ranging from 25 to 45 degrees measured with the help of Planmeca software using CBCT. Teeth with calcified canals and open apices were excluded from the study. On the basis of the degree and the radius of curvature the teeth were randomly divided into two groups of 20 samples each as follows:

Group 1: canals were instrumented using One Shape.

Group 2: canals were instrumented using Mani Silk.

Access preparation and root canal instrumentation: Coronal access was achieved using diamond burs. Glide path was established using 10k followed by 15k stainless steel hand file. Instrumentation was performed in all the samples by a single operator as per the manufacturer's recommendations for both One Shape and Mani Silk rotary files. Moreover, 17\% ethylene diamine tetraacetic acid (EDTA), 2.5\% sodium hypochlorite, and normal saline were used as irrigants.

Pre- (-Fig. 1) and post-instrumentation (-Fig. 2) scans were compared and evaluated for canal transportation and canal centric ability using CBCT (Carestream CS 9300 scanner).

\section{Evaluation of Canal Transportation}

The amount of canal transportation was determined by measuring the shortest distance from the edge of uninstrumented canal to the periphery of the root (mesial and distal) and then comparing this with the same measurement obtained from instrumented images ( - Fig. $\mathbf{3}$ ). All values were measured by two evaluators, and a mean value was taken. The following formula was used for the calculation of transportation: $(\mathrm{x} 1-\mathrm{x} 2)$ $-(y 1-y 2)$, where $\mathrm{x} 1$ is the shortest distance from the mesial edge of the root to the mesial edge of the uninstrumented canal, $\mathrm{y} 1$ is the shortest distance from distal edge of the root to the distal edge of the uninstrumented canal, $\mathrm{x} 2$ is the shortest distance from the mesial edge of the root to the mesial edge of the instrumented canal, and $\mathrm{y} 2$ is the shortest distance from distal edge of the root to the distal edge of the instrumented canal. According to this formula, a result other than 0 indicates that transportation has occurred in the canal.

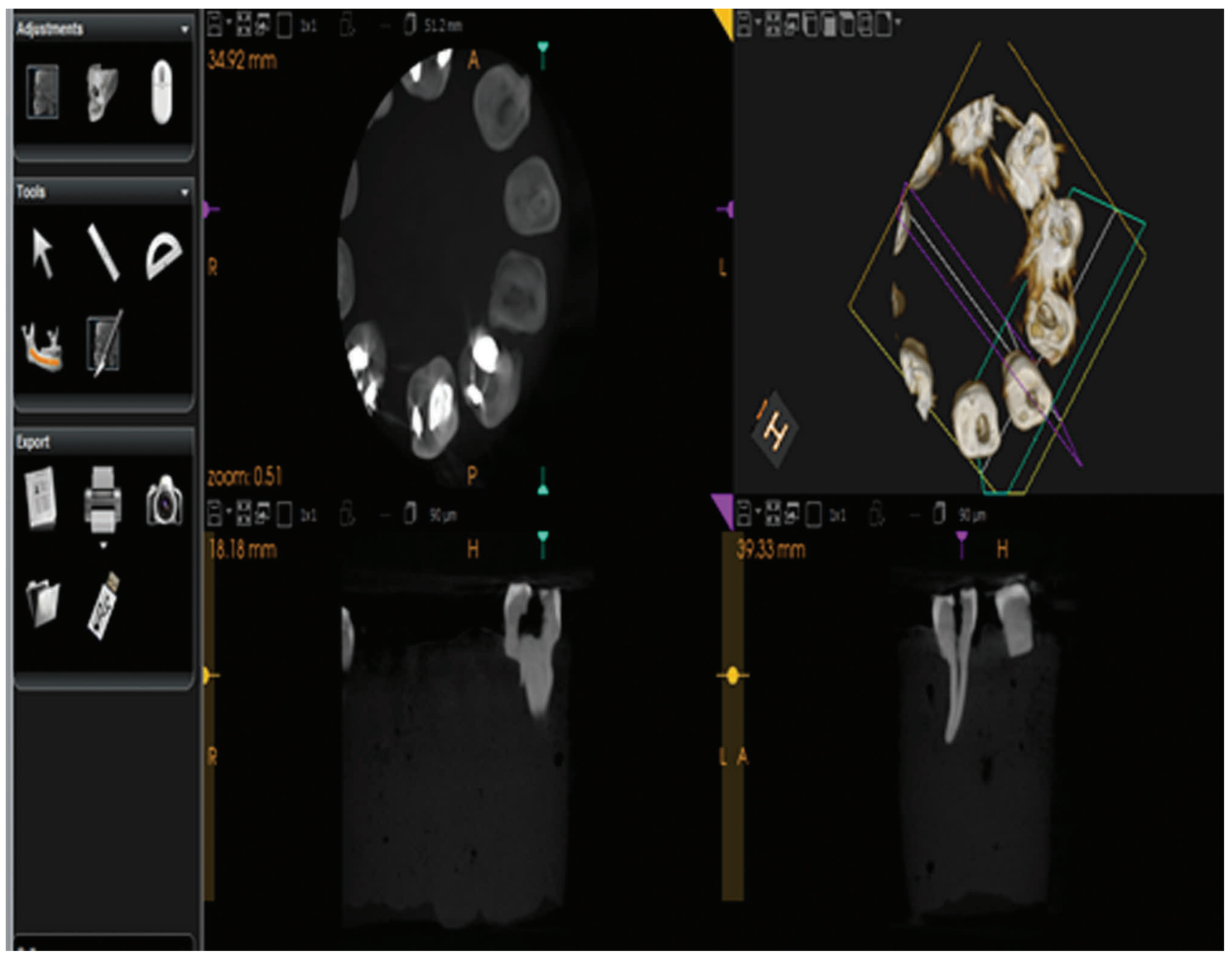

Fig. 1 Pre-instrumentation scan being compared and evaluated for canal transportation and canal centric ability using CBCT. 




Fig. 2 Post-instrumentation scan being compared and evaluated for canal transportation and canal centric ability using CBCT.

\section{Mesial}

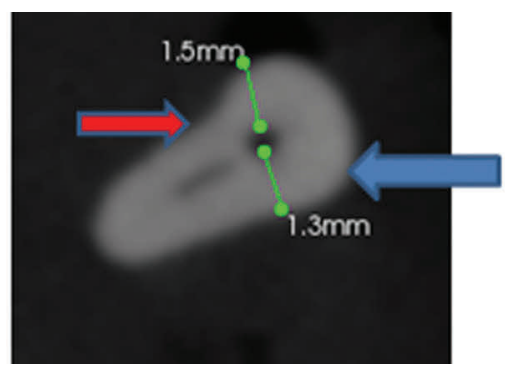

Fig. 3 Amount of canal transportation being determined.

\section{Evaluation of Centric Ability}

The mean centering ratio indicates the ability of the instrument to stay centered in the canal. It was calculated for each section by using the following ratio: $(\mathrm{x} 1-\mathrm{x} 2) /(\mathrm{y} 1-\mathrm{y} 2)$ or $(\mathrm{y} 1-\mathrm{y} 2) /$ $(\mathrm{x} 1-\mathrm{x} 2)$. If these numbers are not equal, the lower figure calculated is considered as the numerator of the ratio. According to this formula, a result value of 1 indicates perfect centric ability.

\section{Statistical Analysis}

Results were analyzed statistically using unpaired Student's t-test.

\section{Results}

The mean transportation values for group 1 at apical, middle, and coronal levels were $-0.32,0.28,-0.10$, respectively, and those for group 2 were $-0.08,0.22,-0.10$, respectively ( - Table 1 ). The mean centering ratios for group 1 at apical, middle, and coronal levels were $0.53,0.85,0.06$, respectively, and those for group 2 were $0.86,0.98$, and 0.59 , respectively (-Table 2 ). Hence from the statistical analysis of the values, it can be said that Mani Silk

Table 1 Canal transportation (mean \pm SD)

\begin{tabular}{|l|l|l|l|}
\hline Group & Apical & Middle & Coronal \\
\hline One Shape & $-0.32+0.84$ & $0.28+0.31$ & $-0.10+0.33$ \\
\hline Mani Silk & $-0.08+0.56$ & $0.22+0.19$ & $-0.10+0.58$ \\
\hline
\end{tabular}

Abbreviation: SD, standard deviation.

Table 2 Centric ability (mean \pm SD)

\begin{tabular}{|l|l|l|l|}
\hline Group & Apical & Middle & Coronal \\
\hline One Shape & $0.53+1.10$ & $0.85+1.19$ & $0.06+1.48$ \\
\hline Mani Silk & $0.86+0.01$ & $0.98+0.95$ & $0.59+3.13$ \\
\hline
\end{tabular}

Abbreviation: SD, standard deviation. 
NiTi rotary file has better centric ability and showed less canal transportation than One Shape NiTi rotary file.

\section{Discussion}

The basic aim of filing the canal is to create uniform tapering shape of canal, which enables efficient removal of microbes. The newer advances in the design features of NiTi rotary files have made it possible to shape the canal using single-file system. Hence, the aim of this study is to compare the shaping ability of a two-file system with a single-file system.

Shaping ability is determined by two variables such as canal transportation and centric ability. Canal transportation can lead to improper cleaning and sealing of root canals whereas failure to respect centricity of the canal causes reduced remaining dentinal thickness. $\mathrm{CBCT}$ allows a noninvasive and reproducible three-dimensional evaluation of external and internal tooth morphology in all three planes.

The CBCT method used for assessing canal transportation and centric ability is by far the most reliable method available. It gives consistent results every time the scan is made. ${ }^{6}$ The scan results collaborated with statistical analysis showed that Mani Silk file respected canal curvature better than One Shape rotary file. Loss of working length and assessing shaping ability is an important parameter when considering automatic biomechanical preparation of root canals because they lack tactile sentivity. ${ }^{7}$ The performance of rotary systems depends a lot on the way it is being used apart from the instrument design; hence, single operator performed the experiment in this in vitro study.

One Shape file system is manufactured using M-wire technology. It is a single file to be used in continuous rotation, anti-breakage control, and noncutting safety tip. ${ }^{8}$ Another rotary NiTi system used in the study is Mani Silk. Silk's tear drop cross-sectional design eliminates the "screwing-in" effect common with many other systems while removing debris efficiently. ${ }^{9}$ Better canal centering ability and less canal transportation of this file can be because of the noncutting tip and heat treatment.
It is evident from the results that Mani Silk respects canal morphology better than One Shape NiTi rotary file.

\section{Conclusion}

Within the limitations of this study, it can be concluded that Mani Silk NiTi rotary file has better centric ability and showed less canal transportation than One Shape NiTi rotary file.

\section{Conflict of Interest}

None declared.

\section{References}

1 Nabeshima CK, Caballero-Flores H, Cai S, Aranguren J, Borges Britto ML, Machado ME. Bacterial removal promoted by 2 single-file systems: Wave One and One Shape. J Endod 2014;40(12):1995-1998

2 Schilder H. Cleaning and shaping the root canal. Dent Clin North Am 1974;18(2):269-296

3 Lin LM, Rosenberg PA, Lin J. Do procedural errors cause endodontic treatment failure? J Am Dent Assoc 2005;136(2): 187-193, quiz 231

4 Gambill JM, Alder M, del Rio CE. Comparison of nickel-titanium and stainless steel hand-file instrumentation using computed tomography. J Endod 1996;22(7):369-375

5 Walia HM, Brantley WA, Gerstein H. An initial investigation of the bending and torsional properties of Nitinol root canal files. J Endod 1988;14(7):346-351

6 Scarfe WC, Levin MD, Gane D, Farman AG. Use of cone beam computed tomography in endodontics. Int J Dent 2009;2009:634567

7 Abu Haimed AS, Abuhaimed TS, Dummer PE, Bryant ST. The root canal shaping ability of Wave One and Reciproc versus ProTaper Universal and Mtwo rotary NiTi systems. Saudi Endod J 2017;7:8-15

8 Bürklein S, Benten S, Schäfer E. Shaping ability of different single-file systems in severely curved root canals of extracted teeth. Int Endod J 2013;46(6):590-597

9 Chandrasekhar P, Shetty RU, Adlakha T, Shende S, Podar R. A comparison of two NiTi rotary systems, ProTaper Next and Silk for root canal cleaning ability-an in vitro study. Ind J Conserv Endod 2016;1(1):22-24 